\title{
Leadership and Change Mobilization: The Mediating Role of Distributed Leadership
}

\begin{abstract}
Leading change is an enduring managerial challenge that encompasses individual and collective efforts within an organization. Among the levers that managers can use to foster change, mobilizing activities are considered particularly relevant since they enable leaders to activate the resources and processes necessary for change to actually occur. This study investigates whether individual person- and task-centred orientations to leadership relate to an emphasis on mobilizing change through their effect on distributed leadership. These hypotheses are tested using an international survey involving 459 middle managers from different firms, countries and industries who had implemented a planned organizational change project. The findings reveal that both person-centred and task-centred orientations to leadership relate positively to mobilizing change, and that distributed leadership may explain the relationship between orientations to leadership and mobilizing activities.
\end{abstract}

Keywords - Leadership, Person- and task-centred orientations, Organizational change, Distributed leadership 


\section{Introduction}

Organizational change continues to be a key challenge for management (Burnes, 2004; Pasmore, 2015). Scientific investigations have provided insights into and understandings of change processes, change management, change leadership, and leadership of organizational change and development efforts. Various typologies and concepts have been identified and empirically studied (Burke, 2013; Burnes, 2004; Greenwood \& Hinings, 1996), and recent literature has focused increasingly on the concept and processes of change management, and factors contributing to its success (Stilwell, Pasmore, \& Shon, 2016).

Among the drivers of planned change identified in the literature (e.g. Battilana et al., 2010), mobilizing - meaning activities that enable leaders to activate the resources and processes necessary for change to actually occur - plays a crucial role. In fact, organizational members can develop the capabilities needed to successfully engage in new ways of doing things through mobilizing activities (Huy, 1999). Therefore, it is important to understand the factors affecting these drivers.

Leadership plays a crucial role in the process of mobilizing resources toward change (Battilana et al., 2010; Conner, 2006; Higgs \& Rowland, 2011; Shani \& Stjernberg, 1995). In fact, organizational leaders tend to shoulder responsibility for developing, implementing and monitoring transformation and change strategies, and often for designing such mobilizing activities (Yukl, 2006). They also function as change agents (Kanter, Stein, \& Jick, 1992), directly influencing, through their behaviours, factors in the work environment that enable and support change (Battilana et al., 2010). In doing so, change agents behave with the aim of fostering cooperation and commitment to change, designing effective routines and structures to facilitate change, and promoting collaboration between organizational members (Battilana et al., 2010; Nadler \& 
Tushman, 1990). Overall, change agents should put in place both task-centred and person-centred behaviours (Bass, 1990; House \& Aditya,1997; House \& Baetz, 1979). However, although the literatures on both leadership and change are well-established, the real impact of the former on the latter is still questioned, and how different individual leadership orientations affect mobilizing activities deserves further exploration (Battilana et al., 2010; Ford \& Ford, 2012; Higgs \& Rowland, 2011).

In relation to mobilizing change, an individual leadership perspective needs to be complemented with a plural leadership view, because the distribution of leadership in organizations is a trigger for building a shared vision and direction of change (Buchanan et al., 2007). At the most basic level, distributed leadership relates to interactions between multiple leaders in specific organizational situations (Denis, Langley, \& Sergi, 2012). Although a growing body of literature at the intersection between leadership and change focuses on complementing the individual leadership orientation with a plural approach to change leadership (Bolden, 2011; Binci, Cerruti, \& Braganza, 2016; Denis et al., 2012; Gronn, 2002, 2009; Higgs \& Rowland, 2011; White, Currie, \& Lockett, 2014), the impact of specific individual leadership approaches, such as task- and personcentred leadership behaviours, on the distribution of leadership remains under-explored.

This paper focuses on the relationship between individual task- and person-centred leadership orientations and mobilizing change activities, by proposing distributed leadership as a process to explain this link. We suggest that these approaches relate to an emphasis on mobilizing activities in planned organizational change through distributed leadership (Gronn, 2002).

To test our hypotheses, an international survey was carried out involving 459 middle managers from different firms, countries and industries who had implemented a planned organizational change project. The findings reveal that both person-centred and task-centred orientations to 
leadership relate positively to an emphasis on mobilizing change, and that an orientation to distributed leadership mediates these relationships.

This study validates and extends previous literature on the link between individual task- and

person-centred approaches to leadership and change mobilization (Battilana et al., 2010) by demonstrating that distributed leadership is a fundamental component of the process of building a shared direction for change, i.e. reducing the risk that the leadership orientation favours the status quo rather than the new way of doing things. Thus, the study aims to contribute particularly to the change literature, since its main focus is on leadership competencies that change agents should possess in order to successfully mobilize change (e.g. Balogun, 2010; Balogun \& Johnson, 2004). It also contributes to the leadership literature, since we shed light on the predictive role of specific individual orientations in distributed leadership in organizations.

\section{Theory and hypothesis development}

\section{Mobilizing as a key driver for enactment of planned organizational change}

In the organizational change literature, dominant theories and models (Kotter, 1995; Lewin, 1952; Shani \& Stjernberg, 1995) follow two main approaches: planned and emergent (Burnes, 2004). In a planned approach to organizational change, although sometimes "activated" by unpredictable external events and context-related threats, the change process is managed through planned phases of intervention; whereas emergent change is so rapid and unpredictable that it cannot be managed top-down (Cummings \& Cummings, 2014). It is therefore more useful to focus on the former when studying leadership in change.

From a managerial perspective, the literature emphasizes three key managerial drivers of activities relating to planned transformations: communicating the need for change and the status of outcomes; mobilizing resources and people in the organization to engage in and activate change 
processes; and evaluating the status of the change effort (Ford \& Greer, 2005; Galpin, 1996; Tichy \& Devanna, 1986). Among these drivers, mobilizing activities play a crucial role as tools enabling leaders of planned changes actually to implement them (Ford \& Ford, 2012; Kotter, 1995; Luecke, 2003; Stilwell et al., 2016). Mobilizing activities include leaders' actions to gain support from their co-workers and acceptance of expected behaviours and routines, such as seeking out others to help shape the vision of the new organization, spending time and energy in re-designing organizational processes and systems, creating trust, and identifying and reducing resistance and inertia (Battilana et al., 2010). Mobilizing activities aim to develop stakeholder cooperation and commitment to the planned course of action, aligning organizational members' thoughts and beliefs toward the change (Huy, 1999; Jick, 2009; Stilwell et al., 2016; Weick \& Quinn, 1999). We therefore focus on mobilizing activities as a key driver of the enactment of planned organizational change.

\section{Individual leadership and change mobilization: definitions}

Although leadership is nowadays considered to involve interactions between leaders and followers (Brown \& Treviño, 2006), leaders' individual inclinations and behaviours are still seen as crucial (Binci et al., 2016; Friedrich, Griffith, \& Mumford, 2016; Paunova, 2015; White et al., 2014), particularly with reference to change effectiveness (Ford \& Ford, 2012). In fact, organizational leaders are typically in charge of providing members of the system with a structured process to transform the system's structures, processes, values, culture and routines, as they should be able to convince members to adopt the new practices as new routines (Higgs \& Rowland, 2005; Kotter, 1995). Models in the literature seek to map individual leaders' patterns of attitudes and characteristics (e.g. transformational and transactional, charismatic, servant, pragmatic and ethical leadership; Anderson \& Sun, 2017) with the behaviours they exhibit in successfully leading change, including engagement and mobilization of resources (e.g. Gilley, Gilley, \& McMillian, 2009; Higgs \& Rowland, 2011; Stilwell et al., 2016). 
A relevant focus when studying change leaders' behaviours is the importance of balancing task- and social-related performance (Bass, 1990; House \& Baetz, 1979). Although the task/social dichotomy was introduced by Bales as early as 1950, it is still used in management studies in general, and in change management studies in particular (Battilana et al., 2010; Gartzia \& Baniandrés, 2016; Gratton, Voigt, \& Erickson, 2007; Paunova, 2015). Task-centred behaviours relate to leaders' focus on organizational structure, design and control, and establishing routines to achieve organizational goals and objectives (Bass, 1990). Person-centred behaviours relate to leaders' focus on promoting collaborative interactions between organizational members (Bass, 1990). These dimensions represent two distinct constructs. Any single individual in a leadership position does not necessarily possess both characteristics; consequently, each achieves different results when influencing others (Judge, Piccolo, \& Ilies, 2004). In fact, leaders who are more oriented toward tasks are more effective in producing performance outcomes, while leaders who are more oriented toward people are empathetic and better fulfil their followers' needs, facilitating acceptance of new practices (Bass, 1990; Halpin, 1957).

Previous literature has highlighted how change leadership competencies relate to both taskand person-centred behaviours (Higgs \& Rowland, 2000, 2001, 2005). In fact, successful change agents should mobilize change, creating and monitoring change plans and new procedures, and engaging and supporting people involved in change (Buchanan et al., 2005; Higgs \& Rowland, 2005).

An important work that builds on seminal contributions in this area and specifically analyzes the links between task- and person-centred behaviours and mobilizing activities is Battilana et al.'s (2010) quantitative study of 89 clinical managers in the UK's National Health Service who had implemented planned change projects. Their study focused on three drivers: communicating, mobilizing and evaluating. With specific reference to mobilizing activities, and building on 
evidence from relevant literature, Battilana et al. (2010) suggest a positive relationship between mobilizing and person-centred leadership behaviours, based on an assumption that interpersonal skills and concern for human relations enable leaders to motivate and guide followers during the implementation phase of change by establishing a supportive social climate and promoting management practices that ensure equitable treatment of organization members (Bass, 1990; Ford \& Greer, 2005; Kotter, 1995). They also suggest that task-centred leadership behaviours relate positively to the implementation of mobilizing activities. In particular, evidence shows that leaders focused on task-oriented behaviours act as organizational architects and aim to re-design systems, processes and procedures, carefully monitoring the progress of change (Bass, 1990; House \& Aditya, 1997; House \& Baetz, 1979; Huy, 1999; Kotter, 1995; Nadler \& Tushman, 1990; Tushman \& O’Reilly, 1997; Yukl, 2006). Battilana et al.'s (2010) empirical work supports a positive relationship between a task-centred orientation and mobilizing, but not a relationship between person-centred orientation and mobilizing. We draw on their framework to develop our hypotheses, since this is a seminal work on the importance of different leadership behaviours in mobilizing change in organizations. Therefore, in the next sub-section, we consider both person-centred and task-centred orientations.

Person- and task-centred orientations and mobilizing: hypothesis development

As previously discussed, leaders have different person- and task-centred orientations. Thus, they emphasise different focuses and activities when aiming to mobilize change, depending on their mix of competences and orientations, and how they perceive the process of change, for example as a sequential process or a nonlinear complex phenomenon (Higgs \& Rowland, 2005). In this context, we discuss hypotheses on person- and task-centred orientation separately here.

Building on evidence that interpersonal skills and concern for human relations enable leaders to motivate and direct followers during the implementation phase of change, Battilana et al. (2010) 
theorize that leaders' person-centred behaviours relate to mobilizing activities, in establishing a supportive social climate and promoting management practices that ensure equitable treatment of organizational members (Bass, 1990; Ford \& Greer, 2005; Kotter, 1995). Although Battilana et al. do not empirically confirm this hypothesis, the literature provides evidence that a person-centred leadership orientation may positively affect motivation, and thus inspire people to adopt and implement mobilizing activities (Gilley et al., 2009; Stilwell et al., 2016). It may also favour the establishment of a supportive social climate, promoting management practices that ensure equitable treatment of organization members, and thus activating mobilization (Bass, 1990; Ford \& Greer, 2005; Kotter, 1995). Therefore, to further test this assumption, the following hypothesis is proposed:

Hla. A person-centred orientation to leadership relates positively to the level of emphasis on activities associated with mobilizing change.

With regard to task-centred behaviours, Battilana et al. (2010) theorize and demonstrate that these relate positively to the implementation of mobilizing activities, building on literature showing that task-oriented leaders act as organizational architects and aim to re-design systems, processes and procedures, carefully monitoring the progress of change (Bass, 1990; Nadler \& Tushman, 1990; Yukl, 2006). Task-oriented leaders can use their ability to align systems and processes to support change, putting extra effort into establishing ways to reinforce and normalize new behaviours (Stilwell et al., 2016). Based on these arguments, the following hypothesis is proposed:

H1b. A task-centred orientation to leadership relates positively to the level of emphasis on activities associated with mobilizing change.

\section{Distributed leadership defined}

The literature offers many theories and definitions of the plural approach to leadership and its key variables (Bolden, 2011; Contractor et al., 2012; Denis et al., 2012; Leithwood, Mascall, \& Strauss, 
2009). This approach comprises various forms of leadership that imply the interaction and "combined influence of multiple leaders in specific organizational situations" (Denis et al., 2012, p. 1).

Although the plural approach to leadership has gained attention in the management field, most studies relate to the educational sector (Anderson \& Sun, 2017), and are conceptual rather than empirical (Rose \& Gordon, 2015; VanVactor, 2012). Studies vary in the extent to which the role of plural leadership is captured in organizations' developmental practices (Leithwood et al., 2009). Some do not distinguish which manifestations of plural leadership are most effective (Gronn, 2002; Spillane \& Diamond, 2007), whereas others suggest that its effectiveness may depend on organizational dimensions (Leithwood et al., 2009).

This study focuses on leaders' orientation relating to "the dispersion of leadership roles across organizations, and even beyond their boundaries, as a variety of people relay leadership responsibilities over time to achieve important outcomes" (Denis et al., 2012, p. 31). This is referred to here as "distributed leadership" (Denis et al., 2012, p. 64), emphasizing coordination between different leaders rather than a "generic form of leadership".

Person- and task-centred orientations and distributed leadership: hypothesis development

Over the last decade, a growing body of literature has sought to complement the individual approach to leadership with a pluralistic approach (e.g. Bligh, Pearce, \& Kohles, 2006; Friedrich et al., 2016; Paunova, 2015; White et al., 2014). Its main purpose is to show how the plural approach should complement the individual approach to supply specific competencies, skills and power legitimacy in leading an organization (Binci et al., 2016; Denis et al., 2012). Individual leadership attitudes may be predictors of the plural form of leadership adopted by groups of individuals (White et al., 2014), but the impact of specific individual leadership behaviours on the distribution of leadership remains unclear. The literature suggests that task-related and socio- 
emotional behaviours may play a role in the emergence of collective leadership (Contractor et al., 2010; Paunova, 2015). Our study tests both task- and person-centred orientations to leadership and their impact on orientation to distributed leadership.

Person-centred behaviours are linked to consideration for others and concern for human relations (Huy, 1999). In order to establish a supportive social climate and ensure equitable treatment, leaders may look for spontaneous collaborative interactions between organizational members and coordination with other leaders (Bass, 1990; Gronn, 2002, 2009; Paunova, 2015). Moreover, person-oriented leaders focus on creating relationships with other organizational members (Goleman, 1998). Developing close working relationships over time is likely to be an important antecedent of distributed leadership, because these close working relationships may "evolve over time until leadership manifests itself in the shared role space encompassed by this relationship" (Gronn, 2002, 2009). Based on these arguments, the following hypothesis is proposed:

H2a. A person-centred orientation to leadership relates positively to distributed leadership.

Task-oriented behaviours are linked to a strong focus on task implementation, encouraging leaders to monitor goal achievement and seek support from others in the organization (Bass, 1990). If leaders lack the skills needed to fulfil these tasks, they may join forces in close working relationships. Task-oriented behaviours also aim to build alignment between values, attitudes and behaviours, and the system (Kets de Vries, 2002). Task-oriented leaders' high concern for performance leads them to set deadlines and periodically monitor their projects' progress (Bass, 1990). This implies regular meetings between leaders to discuss performance, standards and objectives, and hence a need for distributed leadership as an institutionalized organizational practice. In fact, task-oriented leaders focus on getting tasks accomplished by (i) identifying 
relevant stakeholders who need to be involved, and (ii) addressing structure, systems and procedures. In addition, complementary task expertise may be connected with legitimacy issues, thus relating to distribution of leadership (Contractor et al., 2010; Denis et al., 2012; Paunova, 2015). Based on these arguments, the following hypothesis is proposed:

H2b. A task-centred orientation to leadership relates positively to distributed leadership.

\section{Distributed leadership and change mobilization: hypothesis development}

Although evidence is limited, previous findings show that a plural approach to leadership when dealing with change is important, and that certain patterns of distributed leadership have a positive effect on organizational change (Buchanan et al., 2007; Heck \& Hallinger, 2010; Fitzgerald et al., 2013; Canterino, Cirella, \& Shani, 2018). Since organizations have become increasingly projectand knowledge-based, involving professional work and a need for innovation, leaders must be able to deal with collective efforts in which individuals contribute to establishing and developing a common purpose and vision (Bolden, 2011). A plural change agency is able to implement complex organizational changes, even in the absence of formal management plans, roles and structures (Buchanan et al., 2007).

In considering the specific relationship between orientation to distributed leadership and mobilizing change, the literature provides some evidence that mobilizing activities deal with the need to create a coalition to support the change. This is a political process that involves creating commitment among those involved and re-designing processes and systems to enable the change (Kotter, 1995; Nadler \& Tushman, 1990). These kinds of activities involve the whole organization at different levels and roles, and so may require various forms of coordination among leaders. In addition, mobilizing activities relating to change implementation may require formal and traditional channels of authority to be bypassed (Zhang \& Faerman, 2007). Coordination and alternation of different leaders over time may also be essential to guarantee that change projects 
move forward successfully (Buchanan et al., 2007; Chreim et al., 2010; Davis \& Eisenhardt, 2011; Denis et al., 2012; Zhang \& Faerman, 2007). Based on these arguments, the following hypothesis is proposed:

H3. Distributed leadership relates positively to the level of emphasis on activities associated with mobilizing change.

The three hypotheses $\mathrm{H} 1, \mathrm{H} 2$ and $\mathrm{H} 3$, in combination, indicate that person-centred and task-centred orientations to leadership have direct and indirect effects on mobilizing. This is coherent with the assumption that the two orientations may be more effective in mobilizing efforts particularly when a direction for change is shared and developed. This enhances leaders' focus on new ways of doing things, rather than on existing routines and relationships that may be affected by structural inertia (Hannan \& Freeman, 1984). This is explicitly linked to the distributed leadership approach, as proposed in this paper. The mechanism of distributed leadership may explain the relationship between leadership orientations and mobilizing activities when leading change. Therefore, the following hypotheses are proposed:

H4a. Distributed leadership mediates the relationship between a person-centred orientation to leadership and the level of emphasis on activities associated with mobilizing change.

H4b. Distributed leadership mediates the relationship between a task-centred orientation to leadership and the level of emphasis on activities associated with mobilizing change.

As previously discussed, in our mediational model we hypothesize two parallel mediating effects from person and task orientation to change mobilization, through distributed leadership. These two orientations differ, but both are critical to implementing organizational change, as underlined in the initiating structure and showing consideration model (House \& Aditya, 1997). Our aim is to 
test the mediational role of distributed leadership and examine possible differential associations. In particular, in this study we intend to take a first step in explaining the relationship between leadership skills and the development of change initiatives, by proposing a distributed approach as an underlying process. We therefore use a cross-sectional design. Although we are aware that such an approach does not allow causal inferences, we ground the expected relationships in the literature and in previous empirical research relating to the proposed constructs. Specifically, we follow dominant perspectives from the literature that convincingly show a positive relationship between leadership style and organizational change (e.g. Oreg \& Berson, 2019).

\section{Method}

\section{Sample and procedure}

Data were collected in collaboration with the Italian branch of an international human resource consulting company operating in several countries. This specific research was part of a broader study focusing on human resources and change. The sample drawn from the HR consulting company's international database included respondents from companies in four G20 countries (Brazil, China, India and Italy). To select our companies and respondents, we used the following sampling method. In line with the focus of our study, we selected cases with a middle management that had had to deal with a major change implementation project in the previous three years. Cases had to belong to specific industries (for example, manufacturing, services, and commerce and tourism) and range in size, as we sought to include very different kinds of change implementation, in line with previous research (e.g. Paglis \& Green, 2002; Hechanova, Caringal-Go, \& Magsaysay, 2018). As a result, 1,280 middle managers (with a change implementation experience in the previous three years) were contacted, of whom 459 provided complete and valid data, producing a response rate of approximately 36 per cent. The respondents' profiles were varied in terms of 
gender, company tenure and age. Specifically, 34 per cent of participants were female and 66 per cent male. Their ages ranged from 24 to 64, with a mean of 39.4, and their tenure was on average 10 years. About 58 per cent $(n=268)$ of respondents worked in small companies (with less than 500 employees) and 42 per cent $(n=191)$ in large companies (with more than 500 employees).

The data collection took place in June and July 2013, using a standardized procedure. First, a pilot survey was distributed to a small group of potential respondents representing various subgroups in the intended sample. Second, data were collected by sending potential participants a standardized email from the HR consulting company's address inviting them to participate in a survey. The email explained the aims of the research, assured full anonymity and included a link to a web-based survey.

\section{Measures}

A five-point Likert scale was used for the measures $(1=$ strongly disagree; $5=$ strongly agree $)$. For double-blind back translations, professional translators were engaged to translate the survey document and items from English into Portuguese, Mandarin, Hindi and Italian.

Person- and task-centred orientations to leadership. Person- and task-centred orientations to leadership were measured using items from the Global Leadership Life Inventory scale (Battilana et al., 2010; Kets de Vries, 2002). Specifically, 12 items were used for person-centred orientation (as discussed in Battilana et al., 2010; e.g. "I worked to generate trust among my people") and seven for task-centred orientation (as in Battilana et al., 2010; e.g. "I made sure that performance standards are adhered to”). The Cronbach's alpha was 0.92 for person-centred and 0.88 for taskcentred orientation.

Distributed leadership. In the absence of a validated measurement for this dimension (Anderson \& Sun, 2017), and with the aim of specifically considering perceived coordination (Denis et al., 2012), distributed leadership orientation was measured using eight items developed 
from Gronn's (2002, 2009) definition of distributed leadership, which allows identification of different forms and levels of coordination in distributed leadership. These items were intended to reflect individual perceptions around a variety of practices aimed at fostering coordination among different leaders. The items were: (1) "I discussed with and helped my peers in solving problems", (2) "Both me and my peers could clearly describe the vision", (3) "The organization provided me and my peers with a set of shared values that guided the change", (4) "All units were expected to achieve high levels", (5) "Me and my peers met regularly to discuss performance", (6) "Me and my peers regularly met to discuss standards and objectives", (7) "I provided structure that encouraged all my peers to participate in improving the process", and (8) "Informal leaders played an important role in improving the change implementation effectiveness".

Although distributed leadership might be considered a group-level phenomenon, these items were measured at the individual level. This is coherent with similar group-level phenomena relating to climate dimensions, which have indeed been measured with items based on individual perceptions (Brondino, Silva, \& Pasini, 2012; Sora et al., 2009). As a new scale was developed for the current study, exploratory factor analysis was conducted on the eight items. The Cronbach's alpha of 0.90 indicated good internal consistency.

Emphasis on mobilizing change. Emphasis on activities associated with mobilizing change was measured by four items originally developed by Battilana et al. (2010) to measure the same variable of interest (e.g. "I spent a significant amount of time in redesigning organizational processes and systems to prepare my organization for the change"). The Cronbach's alpha for this scale was 0.75 (compared with 0.64 in Battilana et al., 2010).

Control variables. We controlled for some demographic and job-related characteristics that might covary with the dependent variable (e.g. Oshagbemi, 2004; Niessen, Swarowsky, \& Leiz, 2010): gender $(0=$ female, $1=$ male), age (in years) and tenure (in years). We also included 
company size $(0=$ small company with less than 500 employees; $1=$ large company with more than 500 employees) as a contextual element that might affect change mobilization. This is in line with studies of shared leadership (Ensley, Hmieleski, \& Pearce, 2006; Friedrich et al., 2016; Hiller, Day, \& Vance, 2006; Nicolaides et al., 2014), in which the size of the company interacts with performance.

\section{Data analysis}

Analysis proceeded in two stages: (a) testing the measurement model, and (b) testing the mediational hypotheses (Piccoli et al., 2017). Using Amos 23 (Arbuckle, 2014), in the first step we evaluated the content validity of distributed leadership, and then analyzed the factorial validity of our measures by conducting confirmatory factor analysis (CFA). In particular, the hypothesized model was compared with alternative models in order to test for common method bias. In the hypothesized four-factor model (M1), all items loaded on the corresponding latent variable: personcentred orientation, task-centred orientation, distributed leadership and emphasis on mobilizing change. This model was compared with a one-factor model (M2) in which all items loaded on the same factor. In cross-sectional research, common method variance can be a problem because the data in a single questionnaire may be closely correlated (Podsakoff et al., 2003). The one-factor model may indicate whether a single factor accounts for covariances among items. We further evaluated the risk of common method bias by testing a model (M3) in which all items loaded on their expected factor as well as on a latent common method factor (Podsakoff et al., 2003). This enables estimation of the proportion of variance explained by a common method factor (Conway \& Lance, 2010; Podsakoff et al., 2003), since it assumes that the method factor does not interact with the predictor and criterion constructs.

Furthermore, to examine the divergent validity of the constructs, the hypothesized fourfactor model (M1) was compared with a three-factor model (M4) in which person-centred and task- 
centred orientation to leadership were replaced with a single orientation factor. Competing models were compared based on the chi-square difference test $\left(\Delta \chi^{2}\right)$, in addition to the fit indices, and the estimation procedure selected was the maximum likelihood method.

In the second step, mediation analyses with latent variables were performed through structural equation modeling. Specifically, a mediational model with direct and indirect effects was tested for our hypotheses. We used bootstrapping for inferences of the significance of indirect effects. This method is more powerful and preferred over the normal theory-based Sobel, because it does not impose an assumption of the normality of the sampling distribution (Preacher \& Hayes, 2008). We performed 99 per cent bootstrap confidence intervals (5,000 samples) for indirect effects to evaluate whether they included zero.

The mediational model was also compared with an alternative model including the control variables (gender, age, tenure and company size), in order to test their effects on the hypothesized relationships. In cases of significant effects, multiple-group analyses were conducted to examine whether the results obtained were invariant across groups.

It is important to clarify that although the word "effect" may suggest a causal relationship, we do not make inferences about causality, given the cross-sectional nature of the data. We adopt this terminology simply for reasons of clarification.

\section{Results}

\section{EFA for the distributed leadership orientation scale}

The distributed leadership scale was developed for the current study. Therefore, CFA with principal axis factoring as a method of factor extraction was conducted on the eight items. The KaiserMeyer-Olkin measure verified the sampling adequacy of the analysis - KMO $=0.92$ ("marvellous" according to Kaiser \& Rice, 1974) - and Bartlett's test of sphericity was significant ( $\mathrm{p}=0.000)$. 
All KMO values for individual items were greater than 0.89 , which is well above the acceptable limit of 0.5 (Kaiser \& Rice, 1974). The scree plot of eigenvalues was clear and showed the preponderant presence of only one factor, which explained 57.89 per cent of the variance.

\section{Descriptive statistics}

The means, standard deviations and correlations for all scales (with Cronbach's alpha) are shown in Table 1. All correlations between the model's key variables were positive, as expected.

\section{Insert Table 1 about here}

\section{Measurement model}

The hypothesized model (M1) with four factors (person-centred orientation, task-centred orientation, distributed leadership and mobilizing change) provided a good fit to the data: $\chi^{2}(428)=$ 1050.97, $\mathrm{CFI}=0.93, \mathrm{NNFI}=0.92, \mathrm{SRMR}=0.03, \mathrm{RMSEA}=0.05$. The loading of the variables on their corresponding factor was satisfactory (ranging from 0.59 to 0.75 ).

The competing models were: (M2) a one-factor model $\left(\chi^{2}(435)=1754.91, \mathrm{p}<0.001\right)$; $(\mathrm{M} 3)$ a measurement model with a common method factor, that is, a five-factor model with the unmeasured latent factor $\left(\chi^{2}(398)=906.44, \mathrm{p}<0.001\right)$; (M4) a three-factor model $\left(\chi^{2}(431)=1141.31\right.$, $\mathrm{p}<0.001)$. Comparing the fit indices and chi-square difference, the hypothesized measurement model fitted the data better than M2 and M4 (see Table 2). Moreover, the results of M2 and M3 indicated that common method bias was unlikely to significantly distort participant responses. Specifically, the one-factor model (M2) showed no acceptable fit indices. The fit of the hypothesized model was not superior to the fit of M3, the model tested to estimate the proportion of variance explained by common method factor. Although the chi-square difference test was significant $\left(\Delta \chi^{2}(30)=144.53 ; \mathrm{p}<0.001\right)$, the latent common method factor in M3 explained only 10 per cent of the variance, which is well below the threshold of 25 per cent suggested by Williams, 
Cote and Buckley (1989). Consequently, we decided to use the four scales proposed in M1 to test the mediational hypotheses.

\section{Insert Table 2 about here}

\section{Testing of the hypotheses}

A mediational model with direct and indirect effect was tested for our hypotheses. In the results, both leadership orientations were significantly related to mobilizing change. Specifically, the relationship between person-centred orientation and emphasis on mobilizing change was positive $(0.26, \mathrm{p}<0.001)$, supporting H1a, as well as the relationship between task-centred orientation and emphasis on mobilizing change $(0.22, \mathrm{p}<0.001)$, in accordance with H1b. Moreover, the paths from both orientations to distributed leadership were also significant and positive $(0.20, \mathrm{p}<0.001$ for person-centred orientation and $0.23, \mathrm{p}<0.001$ for task centred orientation), in line with $\mathrm{H} 2 \mathrm{a}$ and $\mathrm{H} 2 \mathrm{~b}$. These findings show that both individual orientations are positively related to distributed leadership, supporting the idea that these skills are relevant to a plural leadership approach.

Furthermore, distributed leadership had a direct effect on emphasis on mobilizing change $(0.25, \mathrm{p}<0.001)$, as proposed in $\mathrm{H} 3$. In addition, distributed leadership mediated the relationship between person-centred orientation and mobilizing change (indirect effect $=0.05$, bootstrap CI: $0.03 \sim 0.06$ ) and between task-centred orientation and mobilizing change (indirect effect $=0.06$, bootstrap CI: $0.02 \sim 0.05)$. These results support $\mathrm{H} 4 \mathrm{a}$ and $\mathrm{H} 4 \mathrm{~b}$ and indicate that distributed leadership is the mechanism through which leadership orientations may drive change mobilization. Figure 1 shows the model specified with standardized path coefficients. This is a partial mediational model and provides a good fit to the data: $\chi^{2}{ }_{(428)}=1034.93 ; \mathrm{NNFI}=0.92 ; \mathrm{CFI}=0.93$; $\mathrm{RMSEA}=0.05$ with confidence interval $=0.05 \sim 0.06 ; \mathrm{SRMR}=0.05$.

\section{Insert Figure 1 about here}


This model was compared with an alternative model including the control variables (gender, age, tenure and company size), in order to test their effects on the hypothesized relationships. The results show that only company size $(0=$ small, $1=$ large $)$ had a statistically significant effect. We therefore decided to explore this contextual variable and its influence on our model. Specifically, to examine whether the results obtained from the mediational analyses were invariant across size, we conducted a multiple-group analysis. First, we computed the model separately for employees in small and large companies to compare the fit in each group. Second, to examine whether the magnitude and direction of each hypothesized relationship was invariant across groups, we specified two simultaneous between-group models. In one between-group model, all parameters were freely estimated within size groups. In the other, the hypothesized relationships were constrained to be invariant across size. In analyzing the results, examination of the within-group fit indices showed a good-fitting model for sub-groups of both small $\left(\chi^{2}(428)=976.11 ; \mathrm{NNFI}=\right.$ 0.90; $\mathrm{CFI}=0.89 ; \mathrm{RMSEA}=0.06 ; \mathrm{SRMR}=0.06)$ and large companies $\left(\chi^{2}(428)=983.45 ; \mathrm{NNFI}=\right.$ 0.92; $\mathrm{CFI}=0.91 ; \mathrm{RMSEA}=0.05 ; \mathrm{SRMR}=0.05)$. The $\chi^{2}$ values for the unconstrained $\left(\chi^{2}(856)=\right.$ 1632.16) and constrained $\left(\chi^{2}(861)=1660.42\right)$ simultaneous between-group analyses were then compared based on the between-group chi-square difference test. The results indicated that there were significant differences $\left(\Delta \chi^{2}{ }_{(5)}=28.26 ; \mathrm{p}<0.001\right)$ in the parameter estimates for the hypothesized relationships in the model; therefore, the invariance across small and large companies is untenable. The results of the multiple-group analysis are shown in Table 3.

\section{Insert Table 3 about here}

In examining the parameters to locate specific paths that differed significantly across groups, we found that the association between distributed leadership and mobilizing change was stronger for large companies (0.27) than for small companies (0.18), indicating that company size is a 
moderator of this specific relationship. Developments of this result are considered further in the discussion section.

Lastly, we conducted additional analyses to provide more support for our theoretical hypotheses and rule out alternative mediational models, as our data were cross-sectional. In particular, the model specified for our mediational relationships was compared with two other structural models. In the first, person-centred and task-centred orientation to leadership were replaced with a single orientation factor. Based on the chi-square difference test $\left(\Delta \chi^{2}(3)=106.38\right.$; $p>0.05)$, the fit of this model was not superior to the fit of our hypothesized model in which leaders might differentially emphasize the activities involved in the organizational change implementation, depending on their mix of competencies and orientations.

For the second comparison, we tested a different processual model, as our cross-sectional design does not allow reliance on causal inferences. Based on a different view, it might be plausible to assume that the alignment pursued through distributed leadership practices determines task and person leadership orientations and these, in turn, may lead to mobilization of change (Leithwood et al., 2006). This model was compared with that hypothesized for this study by evaluating the Akaike information criterion (AIC), as they are non-nested models. The model with the smaller criterion suggests a better fit and is therefore preferred. The results show that this model had acceptable fit indices $(\mathrm{NNFI}=0.89 ; \mathrm{CFI}=0.90 ; \mathrm{RMSEA}=0.07 ; \mathrm{SRMR}=0.07 ; \mathrm{AIC}=1607.61)$, although not as good as those of the hypothesized model $(\mathrm{NNFI}=0.92 ; \mathrm{CFI}=0.93$; $\mathrm{RMSEA}=$ 0.05; $\mathrm{SRMR}=0.05 ; \mathrm{AIC}=1248.97)$. However, comparison of the AIC showed that the lower value of our model specified for this study had a better fit. These results may provide further support for the explanatory role of distributed leadership in the relationship between different leadership orientations and change mobilization. 


\section{Discussion}

This study aimed to gain insights into individual and plural approaches to leadership and emphasis on mobilizing activities during planned organizational change. The first and most important contribution of the study, which adds new insights to previous studies of the topic, relates to clarification of the role of distributed leadership on the relationship between individual task- and person-centred orientations and mobilizing activities in the context of change. This is in line with some previous literature indicating that plural leadership affects change dynamics (Buchanan et al., 2007; Chreim et al., 2010; Davis \& Eisenhardt, 2011; White et al., 2014; Zhang \& Faerman, 2007). In particular, distributed leadership may help to focus person- and task-centred approaches on the specific direction for change, avoiding the risk of individual leadership orientations reinforcing the status quo, i.e. focusing on maintaining existing structures and routines, rather than favouring new practices through coordination of tasks and/or development of relationships and social climate at work. This consideration is in line with Denis et al.'s (2012) suggestion that studying distributed leadership is "more revealing of the content of what is taking place than the more generic notion of leadership" (Denis et al., 2012, p. 64), and provides insights into how distributed leadership is affected by individual orientations toward leadership.

Second, the results of this study show that the relevance of distributed leadership in this relationship is higher in large companies. In fact, size is a moderator of the relationship between distributed leadership and mobilizing change activities. We explain this result by considering that, in large companies, power is much more diffused among different actors, with more divergent objectives than in small companies. Therefore, coordination among individuals in leadership positions may be particularly relevant to building a shared direction for change (Chreim et al., 2010; Denis, Lamothe, \& Langley, 2001). This result is particularly important, since debate on the 
relationship between size of organizations and distributed leadership is inconclusive (Nicolaides et al., 2014). This study certainly supports the idea that size, as a contextual element, is relevant to distributed leadership in the context of change.

The third implication arising from this study is its demonstration that perceived person- and task-centred orientations to leadership are predictors of perceived distributed leadership. Concerning person-centred orientation, the findings confirm that consideration for others and concern for human relations may bring about coordination with other leaders, promoting a supportive climate and equitable treatment (Bass, 1990; Paunova, 2015). Concerning task-centred orientation, task-oriented leaders may generate spontaneous and temporary forms of collaboration to develop coalitions (Kotter, 1995; Nadler \& Tushman, 1990). In such cases, functions are distributed between leaders with little or no planning, in line with the definition of distributed leadership as a process in which individual leaders share responsibilities and tasks (Carson, Tesluk, \& Marrone, 2007; Denis et al., 2012).

The fourth implication is the study's confirmation and extension of Battilana et al.'s (2010) findings, in particular (i) showing that both person- and task-centred orientations to leadership affect the emphasis on mobilizing activities; and (ii) testing the relationships with a sample based on respondents from different organizations and industries. The last point is particularly interesting in relation to the setting of Battilana et al.'s (2010) study, i.e. the healthcare sector. In fact, healthcare is a sector, together with education, in which distributed leadership seems particularly relevant, because of the plurality of leaders with different expertise who must coordinate in order to share procedures and guarantee appropriate treatments (e.g. Fitzgerald et al., 2013). Distributed leadership (not measured in Battilana et al.'s study) might shed light on some results from their study, particularly concerning the hypothesis about people orientation and mobilizing (not confirmed in their results). 
Our results also have managerial implications. The findings show that, when dealing with mobilizing activities, orientation to distribution of leadership does matter and should be carefully analyzed. This suggests that management should choose leaders who practise distributed leadership as a strategic choice when they are about to embark on a planned change effort. Such orientation may be beneficial to the organization, enabling temporary or local voids in power to be overcome without preventing the change implementation from progressing, although ad hoc coordination mechanisms to distribute leadership may conflict with the organization's hierarchical setting. Thus, management should carefully analyze and take account of these dynamics when mobilizing change, exploring different ways to engage organizational members in the planned change process and distributed leadership, who may act as enablers of a successful process.

\section{Limitations and future research}

As with all studies, this research has some limitations that highlight directions for future research. First, the cross-sectional nature of our data limits ability to make causal inferences. However, this study relied on theory and empirical research to explain the processes between leadership orientations and emphasis on mobilizing change. In particular, the results are consistent with longitudinal studies that support the positive effects of different approaches to leadership in driving organizational change (Griffin, Parker, \& Mason, 2010; Heck \& Hallinger, 2010). Nevertheless, longitudinal designs in future research would allow the effects of organizational change to be tracked and would provide additional evidence of causal relationships.

The measurements used were self-reported. We were aware of this potential source of common method variance that might affect our findings, as the same person provided information regarding the predictor and criterion variables. In order to control for this bias, several procedural and statistical recommendations were adopted, as suggested by Podsakoff et al. (2003): 
counterbalancing the order of the variables (predictors and criterion), utilizing scales with reversecoded items phrased in a positive manner, avoiding the use of bipolar numerical scale values and providing labels for the midpoints, testing a common method factor model versus a multi-factor model with CFA, and testing alternative structural models. Moreover, self-reports seemed particularly appropriate in this study because the managers were those who were aware of their specific attitudes and behaviours adopted as leaders of their working groups. Future research might assess distribution of leadership in the change process through other types of measurement based on group-level dimensions and analysis.

In our study, data were collected only from middle managers involved in planned organizational change projects. Future research might focus, for example, on quantitative or mixedmethods studies of single organizations, enabling data to be gathered from other actors involved in the process. Moreover, this study only considered firm size as a contextual factor. Further studies might explore the importance of antecedents of distributed leadership, such as a supportive internal team environment (shared purpose, social support and voice) and supportive coaching by an external leader (i.e. team manager) (Carson et al., 2007). Concerning the measure of distributed leadership, this study purposely focused on its coordination aspect, and based items on Gronn's (2002) definition. Although this measure proved reliable, future studies might aim to further test the proposed measurement scale for distributed leadership.

Finally, other possible avenues of research relate to the theoretical lens adopted in this study. While the choice of leadership and change models was justified by theoretical assumptions from the literature, this study might be replicated using different leadership and/or change models, for example to explore other drivers of organizational change (e.g. communicating and evaluating) and/or other change models comprising more than three sets of activities (Kotter, 1995). With regard to individual leadership behaviours, it might be interesting to adopt transformational 
leadership theory and/or charismatic leadership (Fischer, Dietz, \& Antonakis, 2017). The plural leadership perspective provides an arena for further exploration of other forms of plural leadership, such as those categorized by Denis et al. (2012). Lastly, further organizational mechanisms (Cirella et al., 2016; Shani \& Docherty, 2003) that support plural leadership in change mobilization might be explored in future research.

\section{Conclusions}

This study investigated the relationship between task- and person-centred leadership orientations and mobilizing change, and explored the role of distributed leadership in focusing on these two different approaches to organizational change implementation. Our findings suggest that distributed leadership mediates the impact of individual orientations on mobilizing change. These results therefore extend knowledge of the underlying mechanisms explaining this link. Furthermore, by testing the moderating role of company size, we have found support for the idea that in large companies, coordination among individuals in leadership positions is particularly relevant in order to build a shared direction for change. 


\section{References}

Anderson, M. H., \& Sun, P. Y. T. (2017). Reviewing leadership styles: Overlaps and the need for a new "full-range" theory. International Journal of Management Reviews, 19(1), 76-96.

Arbuckle, J. L. (2014). Amos 23.0 user's guide. Chicago, IL: IBM SPSS.

Bales, R. F. (1950). A set of categories for the analysis of small group interaction. American Sociological Review, 15(2), 257-263.

Balogun, J. (2010). When organisations change: A middle management perspective on getting it right. Los Angeles, CA: AIM Research.

Balogun, J., \& Johnson, G. (2004). Organizational restructuring and middle manager sensemaking. Academy of Management Journal, 47(4), 523-549.

Bass, B. M. (1990). Bass and Stogdill's handbook of leadership: A survey of theory and research. New York, NY: Free Press.

Battilana, J., Gilmartin., M., Sengul., M., Pache, A., \& Alexander, J. A. (2010). Leadership competencies for planned organizational change. Leadership Quarterly, 21(3), 422-438.

Binci, D., Cerruti, C., \& Braganza, A. (2016). Do vertical and shared leadership need each other in change management? Leadership and Organizational Development Journal, 37(5), 558578.

Bligh, M. C., Pearce, C. L., \& Kohles, J. C. (2006). The importance of self- and shared leadership in team based knowledge work: A meso-level model of leadership dynamics. Journal of Managerial Psychology, 21(4), 296-318.

Bolden, R. (2011). Distributed leadership in organizations: A review of theory and research. International Journal of Management Reviews, 13(3), 251-269.

Brondino, M., Silva, S., \& Pasini, M. (2012). Multilevel approach to organizational and group safety climate and safety performance: Co-workers as the missing link. Safety Science, 50(9), 1847-1856.

Brown, M. E., \& Treviño, L. K. (2009). Leader-follower values congruence: Are socialized charismatic leaders better able to achieve it? Journal of Applied Psychology, 94(2), 478490.

Buchanan, D. A., Addicott, R., Fitzgerald, L., Ferlie, E., \& Baeza, J. I. (2007). Nobody in charge: Distributed change agency in healthcare. Human Relations, 60(7), 1065-1089.

Buchanan, D., Fitzgerald, L., Ketley, D., Gollop, R., Jones, J. L., Lamont, S. S., Neath, A., \& Whitby, E. (2005). No going back: A review of the literature on sustaining organizational change. International Journal of Management Reviews, 7(3), 189-205.

Burke, W. W. (2013). Organization change: Theory and practice. London: Sage.

Burnes, B. (2004). Emergent change and planned change - competitors or allies? The case of XYZ construction. International Journal of Operations \& Production Management, 24(9), 886902. 
Canterino, F., Cirella, S., \& Shani, A. B., (2018). Leading organizational transformation: An action research study. Journal of Managerial Psychology, 33(1), 15-28.

Carson, J. B., Tesluk, P. E., \& Marrone, J. A. (2007). Shared leadership in teams: An investigation of antecedent conditions and performance. Academy of Management Journal, 50(5), 12171234.

Chreim, S., Williams, B. E. B., Janz, L., \& Dastmalchian, A. (2010). Change agency in a primary health care context: The case of distributed leadership. Health Care Management Review, 35(2), 187-199.

Cirella, S., Canterino, F., Guerci, M., \& Shani, A. B. (2016). Organizational learning mechanisms and creative climate: Insights from an Italian fashion design company. Creativity and Innovation Management, 25(2), 211-222.

Conner, D. R. (2006). Managing at the speed of change: How resilient managers succeed and prosper where others fail. New York, NY: Random House.

Contractor, N. S., DeChurch, L.A., Carson, J., Carter, D. R., \& Keegan, B. (2012). The topology of collective leadership. The Leadership Quarterly, 23(6), 994-1011.

Conway, J. M., \& Lance, C. E. (2010). What reviewers should expect from authors regarding common method bias in organizational research. Journal of Business and Psychology, 25(3), 325-334.

Cummings, T. J., \& Cummings C. (2014). Appreciating organization development: A comparative essay on divergent perspectives. Human Resource Development Quarterly, 25(2), 141-154.

Davis, J. P., \& Eisenhardt, K. M. (2011). Rotating leadership and collaborative innovation: Recombination processes in symbiotic relationships. Administrative Science Quarterly, 56(2), 159-201.

Denis, J. L., Lamothe, L., \& Langley, A. (2001). The dynamics of collective leadership and strategic change in pluralistic organizations. Academy of Management Journal, 44(4), 809837.

Denis, J. L., Langley, A., \& Sergi, V. (2012). Leadership in the plural. Academy of Management Annals, 6(1), 211-283.

Ensley, M. D., Hmieleski, K. M., \& Pearce, C. L. (2006). The importance of vertical and shared leadership within new venture top management teams: Implications for the performance of startups. Leadership Quarterly, 17(3), 217-231.

Fischer, T., Dietz, J., \& Antonakis, J. (2017). Leadership process models: A review and synthesis. Journal of Management, 43(6), 1726-1753.

Fitzgerald, L., Ferlie, E., McGivern, G., \& Buchanan, D. (2013). Distributed leadership patterns and service improvement: Evidence and argument from English healthcare. The Leadership Quarterly, 24(1), 227-239.

Ford, J. D., \& Ford, L. W. (2012). The leadership of organization change: A view from recent empirical evidence. In A. B. Shani, W. Pasmore, \& R. Woodman (Eds.), Research in organizational change and development, Vol. 20 (pp. 1-36). Bingley: Emerald Group Publishing. 
Ford, M. W., \& Greer, B. M. (2005). The relationship between management control system usage and planned change achievement: An exploratory study. Journal of Change Management, 5(1), 29-46.

Friedrich, T. L., Griffith J., \& Mumford, M. D. (2016). Collective leadership behaviours: Evaluating the leader, team network, and problem situation characteristics. The Leadership Quarterly, 27(2), 312-333.

Galpin, T. J. (1996). The human side of change: A practical guide to organization redesign. San Francisco, CA: Jossey-Bass.

Gartzia, L., \& Baniandrés, J. (2016). Are people-oriented leaders perceived as less effective in task performance? Surprising results from two experimental studies. Journal of Business Research, 69(2), 508-516.

Gilley, A., Gilley, J., \& McMillian, H. (2009). Organizational change: Motivation, communication, and leadership effectiveness. Performance Improvement Quarterly, 21(4), 75-94.

Goleman, D. (1998). Working with emotional intelligence. London: Bloomsbury.

Gratton, L., Voigt, A., \& Erickson, T. J. (2007). Bridging faultlines in diverse teams. MIT Sloan Management Review, 48(4), 22-31.

Greenwood, R., \& Hinings, C. R. (1996). Understanding radical organizational change: Bringing together the old and the new institutionalism. Academy of Management Review, 21(4), 1022-1054.

Griffin, M. A., Parker, S. K., \& Mason, C. M. (2010). Leader vision and the development of adaptive and proactive performance: A longitudinal study. Journal of Applied Psychology, 95(1), 174-182.

Gronn, P. (2002). Distributed leadership as a unit of analysis. The Leadership Quarterly, 13(4), 423-451.

Gronn, P. (2009). Leadership configurations. Leadership, 5(3), 381-394.

Halpin, A. W. (1957). Manual for the leader behavior description questionnaire. Columbus, $\mathrm{OH}$ : Bureau of Business Research, College of Commerce and Administration, Ohio State University.

Hannan, M. T., \& Freeman, J. (1984). Structural inertia and organizational change. American Sociological Review, 49(2), 149-164.

Hechanova, M. R. M., Caringal-Go, J. F., \& Magsaysay, J. F. (2018). Implicit change leadership, change management, and affective commitment to change: Comparing academic institutions vs business enterprises. Leadership \& Organization Development Journal, 39(7), 914-925.

Heck, R. H., \& Hallinger, P. (2010). Testing a longitudinal model of distributed leadership effects on school improvement. The Leadership Quarterly, 21(5), 867-885.

Higgs, M., \& Rowland, D. (2000). Building change leadership capability: "The quest for change competence". Journal of Change Management, 1(2), 116-130.

Higgs, M., \& Rowland, D. (2001). Developing change leaders: Assessing the impact of a development programme. Journal of Change Management, 2(1), 47-64. 
Higgs, M., \& Rowland, D. (2005). All changes great and small: Exploring approaches to change and its leadership. Journal of Change Management, 5(2), 121-151.

Higgs, M., \& Rowland, D. (2011). What does it take to implement change successfully? A study of the behaviours of successful change leaders. The Journal of Applied Behavioural Science, 47(3), 309-335.

House, R., \& Aditya, R. (1997). The social scientific study of leadership: Quo vadis? Journal of Management, 23(3), 409-473.

House, R. J., \& Baetz, M. L. (1979). Leadership: Some empirical generalizations and new research directions. In B. M. Staw (Ed.), Research in organizational behaviour (pp. 399-401). Greenwich, CT: JAI Press.

Huy, Q. N. (1999). Emotional capability, emotional intelligence, and radical change. Academy of Management Review, 24(2), 325-345.

Jick, T. (2009). The recipients of change. In W. Burke, D. Lake, \& J. Paine (Eds.), Organization change (pp. 404-417). San Francisco, CA: Jossey-Bass.

Judge, T. A., Piccolo, R. F., \& Ilies, R. (2004). The forgotten ones? The validity of consideration and initiating structure in leadership research. Journal of Applied Psychology, 89(1), 3651.

Kaiser, H. F., \& Rice, J. (1974). Little jiffy, mark 4. Educational and Psychological Measurement, 34(1), 111-117.

Kanter, R. M., Stein, B. A., \& Jick, T. D. (1992). Organizational change: How companies experience it and leaders guide it. New York, NY: Free Press.

Kets de Vries, M. (2002). Global leadership life inventory: Interpreting the twelve dimensions of global leadership. Paris, France: INSEAD.

Kotter, J. P. (1995). Leading change: Why transformational efforts fail. Harvard Business Review, 73(2), 59-67.

Leithwood, K., Day, C., Sammons, P., Harris, A., \& Hopkins, D. (2006). Successful school leadership: What it is and how it influences pupil learning. Nottingham: DfES Publications.

Leithwood, K., Mascall, B., \& Strauss, T., Eds. (2009). Distributed leadership according to the evidence. London: Routledge.

Lewin, K. (1952). Selected theoretical papers. London: Tavistock Publications.

Luecke, R. (2003). Managing change and transition, Vol. 3. Boston, MA: Harvard Business Press.

Nadler, D. A., \& Tushman, M. L. (1990). Beyond the charismatic leader: Leadership and organizational change. California Management Review, 32(2), 77-97.

Nicolaides, V. C., LaPort, K. A., Chen, T. R., Tomassetti, A. J., Weis, E. J., Zaccaro, S. J., \& Cortina, J. M. (2014). The shared leadership of teams: A meta-analysis of proximal, distal, and moderating relationships. The Leadership Quarterly, 25(5), 923-942.

Niessen, C., Swarowsky, C., \& Leiz, M. (2010). Age and adaptation to changes in the workplace. Journal of Managerial Psychology, 25(4), 356-383. 
Oreg, S., \& Berson, Y. (2019). Leaders' impact on organizational change: Bridging theoretical and methodological chasms. Academy of Management Annals, 13(1), 272-307.

Oshagbemi, T. (2004). Age influences on the leadership styles and behaviour of managers. Employee Relations, 26(1), 14-29.

Paglis, L. L., \& Green, S. G. (2002). Leadership self- efficacy and managers' motivation for leading change. Journal of Organizational Behavior, 23(2), 215-235.

Pasmore, W. A. (2015). Leading continuous change. Oakland, CA: Berrett-Koehler Publishers.

Piccoli, B., Callea, A., Urbini, F., Ingusci, E., Chirumbolo, A., \& De Witte, H. (2017). Job insecurity and performance: The mediating role of organizational identification. Personnel Review, 46(8), 1508-1522.

Paunova, M. (2015). The emergence of individual and collective leadership in task groups: A matter of achievement and ascription. The Leadership Quarterly, 26(6), 935-957.

Podsakoff, P. M., MacKenzie, S. B., Lee, J. Y., \& Podsakoff, N. P. (2003). Common method biases in behavioural research: A critical review of the literature and recommended remedies. Journal of Applied Psychology, 88(5), 879-903.

Preacher, K. J., \& Hayes, A. F. (2008). Asymptotic and resampling strategies for assessing and comparing indirect effects in multiple mediator models. Behavior Research Methods, 40(3), 879-891.

Rose, D. M., \& Gordon, R. (2015). Age-related cognitive changes and distributed leadership. Journal of Management Development, 34(3), 330-339.

Shani, A. B., \& Docherty, P. (2003). Learning by design: Building sustainable organizations. Oxford: Blackwell Publishing.

Shani, A. B., \& Stjernberg, T. (1995). The integration of change in organizations: Alternative learning and transformation mechanisms. In W. A. Pasmore, \& D. Woodman (Eds.), Research in organization change and development, Vol. 8 (pp. 77-121). Greenwich, CT: JAI.

Sora, B., Caballer, A., Peirò, J. M., and De Witte, H. (2009). Job insecurity climate's influence on employees' job attitudes: Evidence from two European countries. European Journal of Work and Organizational Psychology, 18(2), 125-147.

Spillane, J. P., \& Diamond, J. B. (2007). Distributed leadership in practice. New York, NY: Teachers College Press.

Stilwell, R. A., Pasmore, W. A., \& Shon, D. (2016). Change leader behavior inventory: Development and validation of an assessment instrument. The Journal of Applied Behavioral Science, 52(4), 373-395.

Tichy, N. M., \& Devanna, M. A. (1986). The transformational leader. New York, NY: John Wiley.

Tushman, M. L., \& O’Reilly, C. (1997). Winning through innovation: A practical guide to leading organizational change and renewal. Cambridge, MA: Harvard Business School Press.

VanVactor, J. D. (2012). Collaborative leadership model in the management of health care. Journal of Business Research, 65(4), 555-561. 
Weick, K., \& Quinn, R. (1999). Organizational change and development. Annual Review of Psychology, 50, 361-386.

White, L., Currie, G., \& Lockett, A. (2014). The enactment of plural leadership in a health and social care network: The influence of institutional context. The Leadership Quarterly, 25(4), 730-745.

Williams, L. J., Cote, J. A., \& Buckley, M. R. (1989). Lack of method variance in self-reported affect and perceptions at work: Reality or artefact? Journal of Applied Psychology, 74(3), 462-468.

Yukl, G. A. (2006). Leadership in organizations. Boston, MA: Pearson.

Zhang, J., \& Faerman, S. R. (2007). Distributed leadership in the development of a knowledge sharing system. European Journal of Information Systems, 16(4), 479-493. 
Table 1. Means, standard deviations, reliabilities (Cronbach's alpha) among variables

\begin{tabular}{|c|c|c|c|c|c|c|c|c|c|c|}
\hline & $\mathbf{M}$ & SD & 1 & 2 & 3 & 4 & 5 & 6 & 7 & 8 \\
\hline 1. Gender & - & - & - & & & & & & & \\
\hline 2. Age & 36.41 & 10.07 & $0.13^{* *}$ & - & & & & & & \\
\hline 3. Tenure & 9.66 & 6.46 & $0.11^{* *}$ & $0.82^{* *}$ & - & & & & & \\
\hline 4. Company size & - & - & 0.02 & -0.05 & -0.06 & - & & & & \\
\hline 5. Person-centred orientation & 4.03 & 0.65 & 0.03 & 0.02 & 0.04 & 0.02 & $(0.92)$ & & & \\
\hline 6. Task-centred orientation & 4.00 & 0.67 & 0.01 & 0.03 & 0.05 & -0.03 & $0.71^{* *}$ & $(0.88)$ & & \\
\hline 7. Distributed leadership & 3.95 & 0.70 & 0.01 & 0.01 & 0.02 & 0.09 & $0.68^{* *}$ & $0.70^{* *}$ & $(0.90)$ & \\
\hline 8. Mobilizing change & 3.77 & 0.72 & 0.00 & -0.03 & -0.04 & $0.11^{* *}$ & $0.53^{* *}$ & $0.52^{* *}$ & $0.55^{* *}$ & $(0.75)$ \\
\hline
\end{tabular}

Notes. Gender: $0=$ female, $1=$ male; Company size: $0=$ small company, $1=\operatorname{large}$ company; Cronbach's $\alpha$ in parentheses on the diagonal; ${ }^{*} \mathrm{p}<0.05,{ }^{* *} \mathrm{p}<0.01$. 
Table 2. Fit indices for all measurement models

\begin{tabular}{|c|c|c|c|c|c|c|c|c|c|}
\hline Model & $\chi^{2}$ & $d f$ & $p$ & CFI & NNFI & SRMR & RMSEA & $\begin{array}{c}\text { Model } \\
\text { comparison }\end{array}$ & $\Delta \chi^{2}$ \\
\hline M1 hypothesized model & 1050.97 & 428 & $<0.001$ & 0.93 & 0.92 & 0.03 & 0.05 & & \\
\hline M2 one-factor model & 1754.91 & 435 & $<0.001$ & 0.74 & 0.73 & 1.13 & 0.09 & $\mathrm{M} 2-\mathrm{M} 1$ & $703.94^{*}$ \\
\hline M3 common-factor model & 906.44 & 398 & $<0.001$ & 0.89 & 0.88 & 0.05 & 0.07 & M1 - M3 & $144.53^{*}$ \\
\hline M4 three-factor model & 1141.31 & 431 & $<0.001$ & 0.89 & 0.88 & 0.06 & 0.07 & M4-M1 & $90.34^{*}$ \\
\hline
\end{tabular}

Note: ${ }^{*} \mathrm{p}<0.01$ 
Table 3. Fit indices for within- and between-group comparisons for size of company (multiple-group analysis)

\begin{tabular}{|c|c|c|c|c|c|c|}
\hline Group comparison & $\chi^{2}$ & $d f$ & CFI & NNFI & SRMR & RMSEA \\
\hline Small company (within-group, $n=268$ employees) & 976.11 & 428 & 0.89 & 0.90 & 0.06 & 0.06 \\
\hline Large company (within-group, $\mathrm{n}=191$ employees) & 983.45 & 428 & 0.91 & 0.92 & 0.05 & 0.05 \\
\hline Unconstrained between-group model & 1632.16 & 856 & 0.93 & 0.92 & 0.06 & 0.06 \\
\hline Constrained between-group model & 1660.42 & 861 & 0.92 & 0.92 & 0.06 & 0.05 \\
\hline$\Delta \chi^{2}$ (Constrained - Unconstrained) & $28.26^{*}$ & 5 & & & & \\
\hline
\end{tabular}

Notes. Unconstrained between-group model = all parameter estimates freely estimated within size groups; Constrained between-group model $=$ hypothesized relationships constrained to be invariant across size groups; ${ }^{*} \mathrm{p}<0.05$ 
Figure 1. Mediational model with standardized path coefficients

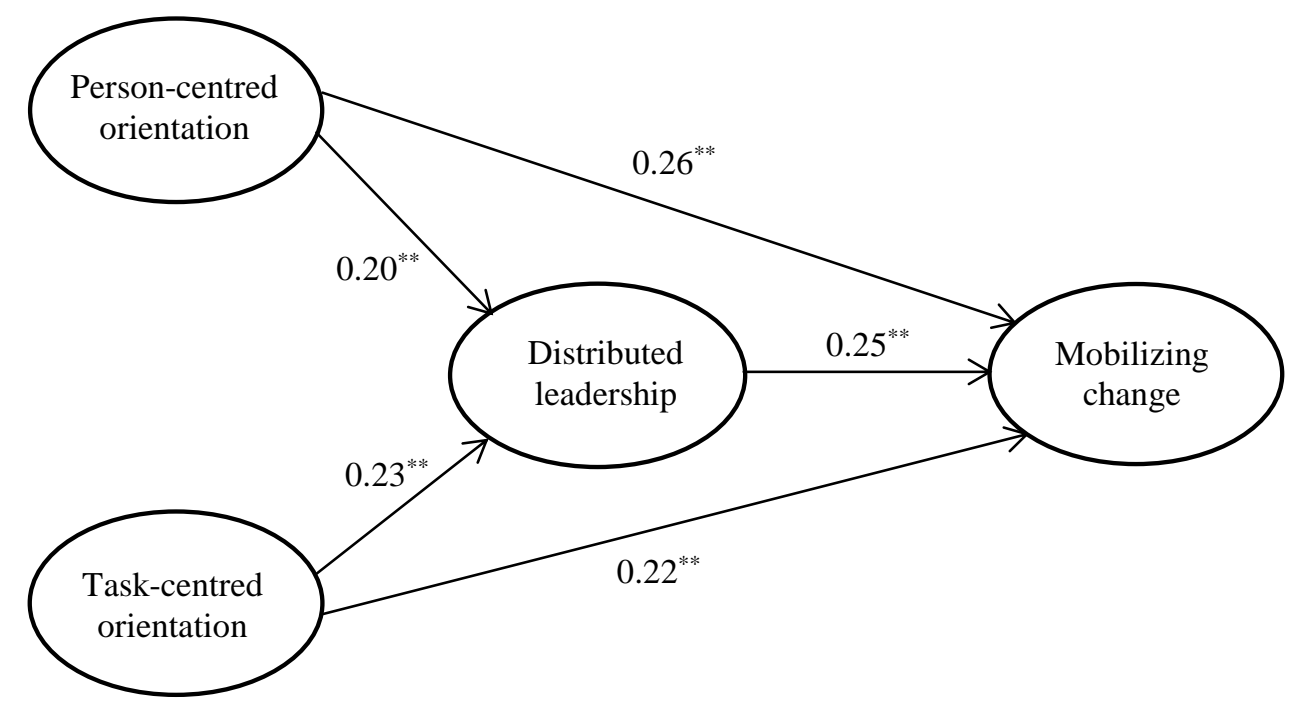

